\title{
A Fellow's Perspective on Beginning a Satisfying Career in Academic Medical Toxicology
}

\author{
Patrick M. Lank
}

Published online: 15 March 2013

(C) American College of Medical Toxicology 2013

Two months before I started fellowship, Harry Karydes wrote an editorial in Journal of Medical Toxicology about his experience growing as a medical researcher during his tenure as a toxicology fellow [1]. As I sit at home writing the "Fellows' Perspective" exactly 2 years later, his editorial reminds me how fortunate I am to have the teaching and mentorship I have had during fellowship. Additionally, it highlights how many practical things I have yet to learn as I move into my new role as a junior faculty member. The relative unknowns of promotion, career satisfaction, and research funding seem nebulous compared to the path laid out for me while completing medical school, residency, and fellowship. Fearing the unknown, looking back at that editorial prompted me to investigate what published objective evidence exists on starting a satisfying academic medical career.

In navigating the waters of academic medicine, my primary goal is continued satisfaction with my work. Although this may be an overly simplistic goal, data suggest it may not be easily achievable. One study by the Association of American Medical Colleges reported that $38 \%$ of all academic medical faculty leave academic medicine over a 10-year period [2]. Although it is expected that a certain percentage of faculty will retire within 10 years, the study highlights that an even higher $44 \%$ of clinical M.D. first-time assistant professors leave academic medicine within the same time period. While decisions to leave academic medicine are multifactorial and personal, it has been suggested that attrition rates are closely tied with a similarly individual and complex outcome measure-job satisfaction [3].

\section{P. M. Lank $(\bowtie)$}

Department of Medical Toxicology, Toxikon Consortium,

Cook County Hospital, 1900 W. Polk, 10th Floor,

Chicago, IL 60612, USA

e-mail: patrick.lank@gmail.com
Studies on professionals in medicine have found a multitude of predictors contribute to career satisfaction [3-5]. From the perspective of a graduating fellow, many of these variables are difficult to judge during an interview day and appear immutable once a position is accepted. Department leadership, individual autonomy, work expectations, and compensation are repeatedly demonstrated as important predictors of job satisfaction [3,4], but these are difficult for a junior faculty member to change. Instead, many young academics choose to focus on approaches to higher job satisfaction that are more modifiable, specifically academic progress and career advancement through promotion [5].

Fortunately, the language of medical academic positions in the USA is relatively universal, with "instructor," "assistant professor," "associate professor," and "professor" being understood and potentially transferrable throughout the country. However, rates of academic promotion, the categories under which faculty members are classified and evaluated, and the actual promotion processes vary greatly among universities. In one study following promotions among internal medicine assistant professors, multiple characteristics were predictive of promotion, including the number of first author publications, geographic location (in the U.S., the Midwest is the most favorable), job satisfaction, time spent doing research, and frequency of performance reviews with the department chair [6].

Some studies also comment on the disparities between clinician educators and clinical investigators and the differences inherent to focusing on a clinical career while simultaneously performing academic work $[2,3$, 6]. While investigators have historically been promoted with higher frequency than their more clinical colleagues, there are suggestions that universities are adjusting their promotion criteria to account for the incongruity between these career paths. However, discrepancies in how promotion criteria are weighted still 
exist between clinical leadership, university leadership, and promotion committees, as evidenced by a study by Atasoylu et al. [7]. In evaluating clinician educators' performance, these researchers found that department chairs highly value clinical skills, certain teaching activities (as reflected by learner assessments), trainee mentoring, and residency or fellowship administrative activities. On the other hand, chairs of promotions committees regard clinical skills and administrative work as less important requirements for promotion, while rating journal publications and external grant support among the highest measures of performance [7].

As an early career academic in the young subspecialty of medical toxicology, these last two criteria, but particularly external grant support, are the hurdles I anticipate will be the highest for me to clear. Many academics begin their acquisition of grant funding by applying for smaller "seed grants" or awards available through multiple sources, such as private funds (e.g., Thrasher Research Fund for early career research in pediatrics) and foundations (e.g., Emergency Medicine Foundation, http://www.emfoundation.org/ EMFGrants/). These initial funding sources are often used for small studies or in preparation for larger, more widely recognized grant applications, such as grants funded by the National Institutes of Health (NIH). For early career academics, the NIH has specific K-kiosk awards (for more information, go to: http:// grants.nih.gov/training/careerdevelopmentawards.htm). These "K-awards" are highly competitive and arguably preferentially given to specialists in larger, more established subspecialties. In part, this is because successful applicants must not only display a wellconceived research plan and established research experience, they must also have high-quality mentorship and institutional commitment to the applicant [8]. It is with this in mind that many academic medical toxicologists align themselves with medical school departments, such as emergency medicine, pediatrics, occupational medicine, and internal medicine, as they provide early career toxicologists with the needed mentorship and support.

While a research-heavy, grant-funded career would inevitably increase the speed with which a young academic would be promoted; there is little evidence that promotion in isolation increases job satisfaction and career longevity. With the unquestionably unpredictable nature of research and promotion, faculty are instead more likely to remain in academic medicine when their goals are aligned with other less tangible aspects, such as feeling relevant and connected, as well as having a feeling of self efficacy [9]. Many programs are now focusing on providing supportive environments for research and faculty development to increase feelings of employee self-worth and of institutional support.

My initial intent in writing this "Fellow's Perspective" was to intellectualize the next phase of my career- to take away the mystery, look at the evidence, and develop a foolproof career plan. Although on the surface, it would appear the plan has written itself (get a good job, do meaningful research, obtain grant funding, get promoted, be satisfied), it is clear there are going to be individual preferences, challenges, and successes that affect how the goal is achieved. As Robert Burns wrote, "the best laid schemes of Mice and Men oft go awry," and there is no golden formula to guarantee a career in academic medicine will be long and satisfying. Like everything else in life, career satisfaction boils down to the intangibles - feeling relevant and connected.

Acknowledgments The author would like to thank Dr. Christine Murphy for her assistance with this editorial.

Conflict of interest There are no conflicts of interest to be disclosed for this editorial.

\section{References}

1. Karydes HC (2011) Fostering an environment for research: a fellow's perspective. J Med Toxicol 7(2):103-104

2. Alexander H, Lang $J(2008)$ The long-term retention and attrition of U.S. medical school faculty. AAMC Anal Brief 8(4):1-2

3. Chung KC, Song JW, Kim HM et al (2010) Predictors of job satisfaction among academic faculty members: do instructional and clinical staff differ? Med Educ 44(10):985-995

4. Lowenstein SR, Fernandez G, Crane LA (2007) Medical school faculty discontent: prevalence and predictors of intent to leave academic careers. BMC Med Educ 7:37

5. Clem KJ, Promes SB, Glickman SW et al (2008) Factors enhancing career satisfaction among female emergency physicians. Ann Emerg Med 51(6):723-728

6. Beasley BW, Simon SD, Wright SM (2006) A time to be promoted. The prospective study of promotion in academia. J Gen Intern Med 21(2):123-129

7. Atasoylu AA, Wright SM, Beasley BW et al (2003) Promotion criteria for clinician-educators. J Gen Intern Med 18(9):711-716

8. Sumandea CA, Balke CW (2009) Funding opportunities for investigators in the early stages of career development. Circulation 119 (9):1320-1327

9. Pololi LH, Krupat E, Civian JT et al (2012) Why are a quarter of faculty considering leaving academic medicine? A study of their perceptions of institutional culture and intentions to leave at 26 representative U.S. medical schools. Acad Med 87(7):859-869 